\title{
Dialogue as a technology for initiating sense- formation in the practice of the educational process of higher education
}

\author{
Laura Kagermazova $^{1, *}$, Zarema Masaeva ${ }^{2}$ and Tsiala Kalmanova ${ }^{1}$ \\ ${ }^{1}$ State Pedagogical University, 364031 Grozny, Russia \\ ${ }^{2}$ Chechen State University, 364093 Grozny, Russia
}

\begin{abstract}
The analysis of modern psychological and pedagogical studies of dialogue as a technology for initiating meaning in the educational process of higher education, as well as the psychological components of dialogue, its didactic content in the meaning of students. Moreover, the dialogue functions in the process of the created semantic field, which forms the intentional, value-semantic, affective components of the student's personality, which allows us to consider dialogue as a true source of actualization of personal potentials in the educational process. Semantic didactics gives a metaphorical definition of dialogue as a "tool of thinking", which encourages the search for psychological characteristics, patterns as the basic foundations of meaning formation that arise in a situation of revealing meaning. The analysis of theoretical studies of the dialogue problem as a meaning-generating technology resulted in the conceptualization of dialogue types in the practice of the educational process, taking into account the didactic tools of pedagogical communication, which in turn makes it possible to form innovative categories in the psychological and pedagogical direction - semantic didactics.
\end{abstract}

Professional and pedagogical activity at all levels from a comprehensive school to a university requires the teacher to organize effective interaction with students, which is expressed in the specifics of pedagogical communication, the presence of dialogue as an essential component of communicative studies in the educational process that unfolds in a personality-oriented paradigm. The nature of the teacher's modern professional activity requires new professional thinking, the value quality of which is the priority of individuality over unanimity, its dynamism and practical orientation. Harmonization and humanization of personality - the upbringing and maintenance of students' motivation in the practice of the educational process, where dialogue relations permeate the "communicative semantic field", where there is cooperation with the student through interaction. Didactic material should be perceived by students, correlated with their practical experience, in the experience itself there should be such components with which, when the dialogue is implemented, new meanings, meanings, knowledge are formed.

\footnotetext{
* Corresponding author: laura07@yandex.ru
} 
Dialogical sense technologies of pedagogical communication are also associated with the process of meaning formation of students.

The sense-forming characteristic of pedagogical communication includes the following components:

1) Creation of meaning;

2) Speech coding of meaning;

3 ) Interaction in a single act of pedagogy communication [1].

"The meaning-generating effect of the problem is the greater, the deeper the problem is for the teacher himself. The meaning-generating and developing effect of training is associated with the personality of the teacher, who carries certain knowledge and cultural patterns and can embody them in interpersonal dialogue, the nature of its conduct and orientation" [2]. "The pathos of the humanistic educational paradigm requires considering the development of personality and thinking primarily in connection with the student's own efforts and is all the more effective, the more the teacher contributes to meeting the student's needs in realizing his creative potential, in cognition in accordance with the existing motivational sphere and individual cognitive strategies, in arguing your opinion through dialogue communication" [3]. "In the process of dialogue, students speak on equal terms with the teacher, and, therefore, the question of dialogue from the Gnostic, traditionally didactic sphere passes into the moral, ethical, new didactic, sociopsychological plane" [4]. "Dialogue as a technology of interpersonal interpenetration of "teacher-student" is based on relevant postulates of the humanization of education, focused on the individual characteristics of the personality of students" [5]. The concept of "problem" as well as "task" originates in the teacher's awareness of the resolution of communicative difficulties and contradictions that arise in the lesson in a particular situation. Any problematic situation is transformed into either a problem or a task. The task can be transferred to the student through dialogue as part of the learning content. In the framework of interactive technologies, the transformation of a problem situation into a task or series of tasks is an act of productive thinking of the student and teacher, where the meanings of "why, for what reason, what patterns exist?" The problem is recognized by students subjectively in the dialogue as a contradictory situation in which there are opposite positions. The problematic situation that has arisen is primary in relation to the initiation of sense formation in students. To solve a problem, it must be turned into a creative cognitive task, allowing testing models of conscious or intuitive solutions. Dialog-experience gives rise to students' awareness of intellectual difficulties in problem situations, problem tasks, the awakening of emotions, cognitive motivation, which in turn contributes to a more effective assimilation of educational material; knowledge will be included in the field of relevant semantic relationships. "Any fact of reality, having entered a person's life's orbit through dialogue, can initiate the emergence of a semantic relationship to him, filling it with new semantic content", "meaning is determined by life" $[4,6]$. Students and the teacher in educational activities have psycho-social needs. They are acquired by each person individually under the influence of personal and social factors: the need for security in the classroom, the need for love, the cognitive need, the need for respect, the need for participation in a group. Meeting needs can be limited by learning difficulties, lack of dialogue as a communicative technology. The result of awareness of this "vital meaning" is a communicative problem. Learning difficulties are analyzed by the teacher in order to solve them productively, for joint discussion with other categories of teachers. "Dialogue, accompanied by problematic, the most significant factor in the formation of meaning" [2]. To organize dialogue as a technology of meaning formation in the context of educational activities and to prevent the occurrence of communication barriers, the teacher should take into account a number of factors. Effects in the perception of the teacher and student: primary - if you first present the positive aspects of the student, and then the negative, the 
attitude towards him will be more favorable than if the information is presented in the reverse order; novelty - about the student who has long been familiar with the student, the latest information is more significant than new information about him. Partially, the perception of the "mediocre student", "excellent student" is stereotyped, which reduces the effectiveness of pedagogical forecasting; halo effect - if the primary information was favorable, then in the subsequent personality traits of the student are reassessed in a favorable direction; stereotyping arises regarding membership in a social group, layer. "Mediocre student" - often characterized by teacher "complicated relationship in the family"; "the edge effect" - the information about the beginning and end of a series of stimuli is better remembered. The pedagogical forecast is often erroneous. Deficiencies in the diagnosis can be associated with the attitude of fixing attention to a particular fact; biased pulling out events confirming the pedagogical forecast.

This provision helps to increase the attention of the administration to the teacher's speech actions, the ability to use dialogue as a didactic technology. The administration's observation of the teacher's speech behavior in the lesson shows the influence of the principles of humanization of education on positive communication in the educational process.

A situational analysis of educational activity helps the teacher in determining the positive and negative manifestations in the lesson.

The teacher should analyze:

1. Weakening of reflection: reduced or increased criticality to oneself, ignoring the opinions of others

2. Highlighting a small number of differences in perceived information.

3. Low level of generalization of information by students

4. Slow and superficial thinking

5. The sense of humor of the teacher and students, the subtlety of the captured nuances in the lesson

6. Various inconsistencies, changes in behavior, inadequate to changes in the lesson situation, inconsistencies in words and gestures (Table 1).

Table 1. The influence of the principles of humanization on the professional communication of the teacher

\begin{tabular}{|c|c|}
\hline Teacher & Pedagogical process \\
\hline Personal relationship & $\begin{array}{l}\text { - Self determination } \\
\text { - Installation on self-education } \\
\text { - Social and moral development }\end{array}$ \\
\hline Soul - Spiritual Relationships & $\begin{array}{l}\text { - Complexity } \\
\text { - Democratization of relations } \\
\text { - Control and self-control }\end{array}$ \\
\hline Dialogue & $\begin{array}{l}\text { - Social conditionality of goals } \\
\text { - Unity of professional views } \\
\text { - Social sustainability in its activities }\end{array}$ \\
\hline Individually - creative process & $\begin{array}{l}\text { - Highlighting core concepts } \\
\text { - Mastering basic concepts beyond the content of } \\
\text { the pedagogical process } \\
\text { - Focus on the essentials } \\
\text { - High difficulty } \\
\text { - Fast paced teaching process }\end{array}$ \\
\hline
\end{tabular}

The general methods of the teacher's influence on students, ways of solving problem situations, building a "dialogue semantic field" in the practice of the educational process are highlighted: 
1. The name (awareness) of one's own behavior; sometimes it's enough to name an act so that the student refuses it.

2. Clarification of the reasons the student pursues, acting in this way.

3. Discussion of the fact, proof of its unproductiveness, difficulties arising from it.

4. An analysis of the objective reasons for a specific fact from a student's past when this behavior was first observed.

5. Reassessment of the reasons, reduction of the act to insignificance or, conversely, imparting significance to the fact.

6. Information - the goal is a minimum of ambiguities between the relations of all participants in the educational situation.

7. Calming - when the student is truly calm, he does not defend himself or manipulate.

8. Breaking the stereotype, the suppression of indecent behavior.

9. Strengthening reflection - shifting attention to the student himself, telling him how he himself can affect others.

10. The introduction of reflection - a description of the student how a specific struggle of motives occurs in him, to give specific calculations $[2,3,7]$.

A. G. Asmolov highlights the constructs of overcoming the student's resistance in the dialogue: "in the interaction of two semantic strategies in the same semantic space of the personality, the process of semantic formation takes on the character of semantic selfactualization and mutual enrichment of the semantic strategies themselves":

- give a talk

- apply resistance to minor details,

- direct the resistance in one direction with the action opposite to the motive,

- create the illusion of many points of application of resistance [5].

The teacher is short of time in the classroom. The result is a refusal to communicate, the student perceives information passively, there is no activity on the part of the students, although they know the teaching material, are not included in an active discussion of the lesson material. This example is relevant from a psychological and didactic point of view, since "the course taken by schools on the personal development of students is accompanied by tasks on "personalization", "reincarnation", "self-expression","self-reflection" and other activities" $[2,8]$.

Define the reaction of students to frustration in class:

- Flight. The student avoids participating in a particular type of activity in the pedagogical process.

- Fixation. The student continues to seek "his" every time, although the situation has long changed.

- Regression. Return to previous modes of action. Unsuccessful learning activities are usually the first sloppy infantile actions, going back.

- Suppression. Inability to confess in unfulfilled desires. Suppression allows you to save the student's ideas about "nuclear meanings," "stable semantic structures of consciousness, its basic self."

- Anxiety, the highest degree - longing. It arises as a result of a lack of psychological security. Fear can embrace the whole psyche of a person, become a strong and constant construct in the formation of meaning. And then the problem of sense formation becomes one of the most significant and promising in psychological and didactic research.

The teacher must have special qualities that make him able to manage the situation, the actions of the student.

The interaction of the teacher with students in educational activities is carried out according to various models.

1. Directive model 
The teacher manages, develops solutions, coordinates, and controls the activities of the group. The quality of decisions depends on the awareness of the teacher. All students must agree with the actions of the teacher. Management contributes to the increase of hierarchical judgments, hinders the cooperation of the teacher and students. The style of directive management forms a frustration, leads to the emergence of informal groups, which at first spontaneously and then deliberately "violate the distance".

\section{Cooperation}

An active exchange of views between teachers and students. Decisions are made together, more difficult, because there is a violation of the ability to understand and mastery of behavior. The leader and the group must learn to communicate with each other. It is important for deep changes in the group. High comfort of group members. Self-reports are better carried out, which require more insight from the teacher and students, based on knowledge of the teacher's behavior.

\section{3. "Non-directive"}

The pedagogical process "is often left to chance." It is important when forming interpersonal skills in groups. It occurs in a group of students in the formation of a leader, it takes a lot of time, is unsuitable for quick decision-making in emergency situations.

\section{Collective opinions}

The perception of a given situation is influenced by the social roles that we play. For different people, the same situation, the same "life meaning" has different meanings; a "dialogue of the deaf" arises. The teacher does not perceive students as independent individuals. "And dialogue as a didactic technology should contribute to the disclosure, understanding and enrichment of the student's personality" $[9,10]$. One of the widespread tactics for solving the communicative problems of a training lesson is to create a dialogue of success for students by the teacher. Dialogue-success in learning, says A.S. Belkin is the only source for the student's inner strength that gives birth to energy to overcome difficulties in the desire to learn how to learn. The concepts of "success" and "situation of success" are distinguished. The first is as an experience of joy, satisfaction from the fact that the result to which the student's personality aspired in the activity coincided with or exceeded the result. The second is considered as a purposefully-organized combination of conditions under which the opportunity is created to self-actualize in the learning process.

Thus, dialogue as a sense technology of the initiation of meaning formation in the practice of the educational process is relevant and in demand to consolidate the educational process at the personal-semantic level. Modernization of higher education will require the creation of new systems of pedagogical technologies that purposefully affect the meaning of students as components of the value-semantic sphere of personality. "At the same time, the content of the educational process and pedagogical technologies should be interconnected: if the content fills the personality, its semantic structures, then the technologies include, trigger the mechanism of its development. Given the nature of the impact of dialogue technologies that initiate meaning formation in the educational process, which are purposeful and facilitating (supporting) in nature, the psychological and pedagogical need arises for the use of dialogue in the practice of the educational process" $[1]$.

\section{References}

1. I.V. Abakumova, Training and sense: sense formation in educational process (RGU Publ., Rostov-na-Donu, 2002)

2. I.V. Abakumova, P.N. Ermakov, I.A. Rudakova, Sense-Centrism in pedagogy. New understanding of didactic methods (RGU Publ., Rostov-na-Donu, 2006) 
3. I.V. Abakumova, V.T. Fomenko, General theory of meaning, psychological concepts of meaning formation, sense didactics, 350-376 (2014)

4. I.V. Abakumova, L.Ts. Kagermazova, P.N. Ermakov, Technologies of the directed translation of meanings in practice of educational process: monograph (Credo Publ., Moscow, 2016)

5. A.G. Asmolov, Personality as a subject of psychological research (Moscow University Press, Moscow, 1999)

6. L.Ts.Kagermazova, I.V. Abakumova, Z.V. Masaeva, Russia, West, East: dialogue of cultures and civilizations. Collection of scientific works of the international scientificpractical conference, 257-259 (2018)

7. D.A. Leontiev, Psychology of meaning (Sense, Moscow, 2003)

8. Z.V. Masayeva, L.Ts. Kagermazova, Humanities, 4 (40), 122-126 (2017)

9. M. Sh. Murphy, Teaching and Teacher Education, 37, 165-168 (2014)

10. I. Stith, W.-M. Roth, Teaching and Teacher Education, 26, 363-370 (2010) 